\title{
ELITE EDUCATION AND EVERYDAY ENCOUNTERS: EXAMINING THE MULTIPLE DIMENSIONS OF PRIVILEGE IN YOUNG PEOPLE'S LIVES
}

He Rourou, Volume 1, Issue 1, 100-105, 2021

HAYLEY SPARKS

\section{THE CONCEPT OF PRIVILEGE}

This research review comes from research completed as part of a $\mathrm{PhD}$ in Geography at The University of Auckland. The research was titled: "Elite education and everyday encounters: Examining the multiple dimensions of privilege in young people's lives"

By embracing uncertainty, the research examined the geographies of privilege through engagement with young people who attend elite private schools in Auckland, New Zealand. The narratives and experiences of young people provided the empirical basis for this project, which is situated alongside extant literatures to develop a conceptual framework of privilege as a key structure shaping the encounters of everyday life. Young people engaged in the research through interactive focus groups and online dialogic diaries. This approach provided data on both an individual and collective level, and provided opportunities to engage in conversation with the young people. Content analysis of school websites and media texts was also conducted to provide insights into the institutional dimension of the contexts the young people were being educated in. In a context where discussing privilege is uncommon, examining the operation of systems of privilege through this research had implications for conceptualising privilege as well as comprehending the realities of everyday life for young people.

Explicitly marking the effects of privilege, understood as a system made up of institutional, symbolic, and individual dimensions, on the plurality of childhoods is critical. Until recently, research has focused on seeking to better understand discourses of oppression and deprivation, rather than privilege and advantage. As a result, privilege has become further normalised, through material, social, political, and economic manifestations in people and places. However, inequalities exist because some groups and individuals are privileged (Johnson, 2006). With this understanding, privilege has recently become the focus of a significant body of research. In public imaginaries, the term privilege conjures ideas of wealth. However, academic conceptualisations of privilege emphasise more than wealth; rather privilege is understood as paradoxical and socially constructed through psychological and social processes (Pease, 2010; Twine \& Gardener, 2013). Privilege is conceptualised as a social and collective discourse which structures individuals' and groups' lived realities. McIntosh's (1989) foundational text explains how privilege consists of two dominant forms of advantage: unearned entitlements and conferred dominance. These components highlight the main premise of privilege understood through an academic lens, in that privilege exists "when one group has something of value that is denied to others simply because of the groups they belong to rather than because of anything they've done or failed to do" (Johnson, 
2006, p. 21). It is therefore not the individual who is privileged, but the social categories that they are ascribed membership to which are privileged.

Three key messages emerged from the research and are summarised in this review:

1. conceptualising privilege as a system;

2. intersectionality;

3. the contextual specificities of privilege

\section{PRIVILEGE AS A SYSTEM}

Privilege can be understood as a system made up of components and practices which have institutional, symbolic, and individual dimensions. Systems of privilege are fluid, complex, and negotiated organisations of practices and components which are affected by a range of factors. In this way, systems of privilege are dynamic and composed of interconnected components. Systems, including systems of privilege, have no fixed spatial or temporal boundaries. In this context, elite private schools are not completely bounded spaces, but the practices of privilege transcend porous boundaries to have significant influences on young people's identities and experiences outside the school gates. Notwithstanding the often gated and walled nature of elite private school campuses, this claim highlights the dynamic and embedded nature of privilege in place. Practices such as consumption, mobility, education, and identity construction are entrenched in the system which enables the reproduction of privilege. The multiple dimensions and practices of privilege highlight how individual and cultural processes are involved in cultivating privilege (Howard et al., 2014). Therefore, it is argued that privilege is not existential per se, but produced and reproduced by multiple active agents working through many media.

The experiences and identities of young people who attend elite private schools presented in the research provide insight into how privilege structures everyday encounters, through the performance and resistance of privileged ways of knowing, being, and doing. Privilege is therefore an active construction which is relative, experiential, situated in place, acquired, learnt, enacted, and shaped by everyday actions and practices. The embodiment of privileged practices by young people is reflected in their narratives of identity and everyday experience. The identities young people construct, perform, and negotiate highlight how privilege influences young people's sense of self (Howard, 2008). This contention illustrates how identity is a product of discourses and sets of practices that are part of the fabric of everyday life, reinforcing Valentine's (2000, p. 257) claim that children are "located in narratives of identity not of their own making". The performance of identity is thus embedded in a complex web of social relations between bodies, texts, events, and technologies.

The structural and agentic components of systems of privilege must be acknowledged and examined to understand how privilege is produced and reproduced. It must also be recognised that privilege is relative, and therefore the operation of systems of privilege does not have the same outcome for all. The narratives reproduced by some participants in this research stress that not all students attending elite private schools experience the same degree of privileged affordances. While such young people are privileged in the sense of the education they are receiving, outside the school gates it became apparent that some participants found it difficult to 'keep up'. Again, linked to the symbolic dimensions of privilege, objects, tastes, and styles are coded with discourses of privilege, which young people on scholarship or being sponsored to attend elite private schools can decode because they have learnt what it means to be privileged. However, at the same time, 
their relatively restricted access to resources means that being able to embody and enact these codes through ownership of objects and behaviours is not always possible. Therefore, this research shows how both inherited and learnt privilege is needed to sustain systems of privilege. Together, the individual, symbolic, and institutional dimensions and practices constitute systems of privilege which operate as part of the broader social fabric.

\section{INTERSECTIONALITY: AGE AND PRIVILEGE}

Seeking to understand how privilege shapes the geographies of young peoples' everyday lives is one means to make privilege visible and uncover the ways in which systems of privilege operate. The participants in the research occupy an ambivalent position within the systems of privilege discussed here. They are active members of society and possess agency to reproduce dominant discourses and social norms. In this way, young people are actively engaged in the practices which contribute to the construction of systems of privilege, even if they are not always consciously aware of their contributions. However, at the same time, by virtue of their chronological age and associated social norms, young people do not 'set the rules' by which systems of privilege operate. Young people can, however, contribute to its reproduction by performing as social selves through the different dimensions. This reproduction was evident in many experiences and encounters young people narrated, including, for example, following technology and clothing trends, aspirations for tertiary education, and extensive international travel experiences. Therefore, considering the intersectionality of age and privilege reveals how privilege is relative and actively constructed. This is because young people's actions and attitudes are shaped by privileged understandings of the world which are developed through socialisation in elite private schools. Further, the influence of structural components of the systems of privilege on young people's agency is also highlighted as young people's attitudes and actions are mediated. The research privileged the voices of the privileged (based on class and education), challenging and disrupting dominant discourses and narratives.

Privileging the voices of the privileged is a counter-cultural narrative to those that are usually produced in social and cultural geography where there is often a focus on 'studying down'. However, the benefits and insights gathered by investigating the narratives of young peoples' experiences, as well as focusing resolutely on privilege, are many and varied. By studying privilege, the nuances are investigated rather than simply reasserting its normative status. Privileging the voices of the privileged is not denying the importance of seeking to understand disadvantage and marginalisation, but rather acts as an alternative approach to further understanding how privilege actively contributes to the perpetuation of inequalities. This move fits with Wildman and Davis' (1995) contention that dominant vocabulary allows us to talk about oppression and disadvantage, but hides the mechanisms that perpetuate it. In this way, the absences and silences surrounding privilege are just as important to consider as visible markers of privilege. Young people's resistances to labelling themselves as privileged or acknowledging how their everyday experiences differ from other young people is telling. For example, the spectacular acts of transnational mobility in the form of international travel was accepted to be a privilege, but the attempts to suggest 'that we are all the same' reinforce how young people do not always see themselves as different. Therefore, it is necessary to find a vocabulary to discuss privilege. Focusing on the interconnected dimensions of systems of privilege is one way these conversations can be started, particularly in a context such as New Zealand, where dominant social norms present a discursive veneer of equal opportunity and discourage the naming of privilege. 


\section{THE SIGNIFICANCE OF CONTEXT}

While broader conceptualisations of privilege, the relationship between privilege and young people's experiences, as well as the role of elite schools in understanding the wider social fabric have significant value, the contextual specificities of the research are also meaningful. It was evident through the research that privilege is lived in a particular way in New Zealand, influenced by culture, history, and geographic location. Therefore, following Borell et al. (2009), to highlight how the specificities of place influence the operation of systems of privilege, it is useful to think about whether the outcomes of this research would look different elsewhere. For example, British experiences of class are in stark contrast to New Zealand, and an American understanding of class differs again (in British and American societies there are much stronger demarcations of class, working class, middle class and elites, than in a New Zealand context). The effect of dominant understandings and approaches to discussing class in different contexts is critical to understanding the operation and effects of systems of privilege. Analysing young people's narratives and institutional tropes in this research exposes two dominant social narratives which prevail in New Zealand and shape how systems of privilege operate.

Firstly, the myth of New Zealand as a classless society structures how New Zealanders describe social relations. It is widely believed, but undermined when unpacking the realities of inequality, that New Zealand is a classless society. As such, discussions of privilege and class are somewhat silenced. In this way, I argue that class-based languages are moulded by dominant discourses. Countering notions of a classless society, young people's narratives expressed in this research reveal the ways in which privilege and class manifest in the form of education and wealth. Secondly, and connected to the myth, is the resistance to discuss individual success and advantage which are always framed as being a result of hard work, rather than unearned entitlements. These two ideas were clear in young people's autobiographical narratives, where there was a reluctance to label their experiences and lifestyles as privileged. Instead, descriptions of being lucky and fortunate dominated. The connection between parents' hard work and the young people being able to attend elite private schools is also illustrative of the tendency to attribute privilege to hard work rather than marking such experiences as an outcome of privilege. The research therefore highlights the centrality of place in the operation of systems of privilege. Just as systems of privilege have varied effects on individuals and groups, the operation of systems of privilege reflects broader social systems embedded in place.

The empirical evidence suggests that when trying to examine systems of privilege in a context such as New Zealand, a nuanced approach is required. Privileged lifestyles occupy an ambivalent position in New Zealand, but this ambivalence needs to be acknowledged and examined in more detail. Examinations must incorporate analysis of wider social, cultural, and economic factors to understand the geographies of privilege, and do so by privileging the voices of the privileged. This poses difficulties and brings to the surface feelings of uncertainty for researchers. However, embracing the unknown, rather than focusing only on those who are disadvantaged and using their experiences as a proxy for inequality, is critical. The reproduction of inequality will continue to be only partially understood unless the mechanisms by which this occurs are examined in greater detail. Without overcoming common perceptions of New Zealand as a classless society, and dominant resistance to discussing individual success and advantage, privilege remains unnamed. This contention does not dismiss the argument that privilege is invisible to those who are privileged (Borell et al., 2009; Johnson, 2006; Pease, 2010), but nuances the claim. Symbols and signs of privilege are evident in both material and embodied ways, such as through housing, employment, mobility, and consumption. Most participants' responses emphasise how privilege 
remains unmarked from the perspective of those who are privileged (Borell et al., 2009), but privilege was covertly marked through experiences, identities, and symbols. One participant explicitly noted that he was privileged given where he lived, the resources he had access to, and the school he attended, but other participants were not as forthright in their claims. Therefore, I conclude that privilege remains largely unnamed, but the unnamed nature of privilege reinforces its dominance. Acknowledging the luxury of obliviousness privileged people can claim (Johnson, 2006) is therefore important to understanding how systems of privilege work. By not naming oneself as privileged, privilege continues to remain unnamed in society. This reinforces how language can mask and mark systems of privilege (Wildman \& Davis, 1995). Explicitly naming and marking the effect of privilege (systems and practices) on childhood is important. Although the research examined privilege within the context of New Zealand, focusing on young people's experiences, the framework can be expanded and nuanced to further understand geographies of privilege in different contexts.

Exploring the construction, negotiation, and performance of young people's identities shows how discourses of privilege shape individuals' biographies, through the intersection of different social categories including class, age, and gender. In particular, the influence of structure and agency highlights some of the tensions and contradictions of privilege which arise because the young people in the study are part of the social elite by virtue of the schools they attend, but are also simultaneously disempowered in some contexts because of their age. In this way, I argue that young people are critical actors in practices which contribute to the reproduction of privilege, but do not have the status to create systems of privilege. Linked to this idea is the centrality of the institutional dimensions of privilege, which has implications for both the individual and symbolic dimensions. Institutions, elite private schools in this research, are shown to reproduce privilege through the normalisation of discourses and practices which reinforce privileged ways of knowing and being. While not all elite private schools operate in the same way, the signs and symbols of independence and exclusivity afford them the ability to prepare students for a future where success and status is continually reproduced. The symbolic dimensions of privilege are not only evident in the practices of institutions, but also in other material and metaphorical signs related to mobility and consumption which young people actively engage with. In this way, the conceptualisation of systems of privilege emphasises how privilege does not rest with individuals, but is encoded in discourses and symbols which shape how individuals and institutions construct, negotiate, and perform privileged identities. Of most importance to understanding the operation of systems of privilege is acknowledging and examining the intersections between different components. These components fit together as a system to shape everyday life, and thus underpin a key contention of the research; that narratives recorded by young people who attend elite private schools reveal how practices and encounters actively construct and reproduce privilege through institutional, symbolic, and individual dimensions.

\section{REFERENCES}

Borell, B. A. E., Gregory, A. S., McCreanor, T. N., Jensen, V. G. L., \& Barnes, H. E. M. (2009).

"It's hard at the top but it's a whole lot easier than being at the bottom":The role of privilege in understanding disparities in Aotearoa/New Zealand. Race/Ethnicity: Multidisciplinary Global Contexts, 3(1), 29-50.

Howard, A. (2008). Learning privilege: Lessons of power and identity in affluent schooling. New York: Routledge. 
Howard, A., Polimeno, A., \& Wheeler, B. (2014). Negotiating privilege and identity in educational contexts. New York: Routledge.

Johnson, A. (2006). Privilege, power and difference (2nd ed.). New York: McGraw Hill.

McIntosh, P. (1989). White privilege: Unpacking the invisible knapsack. Peace and Freedom, July/ August, 1-4.

Pease, B. (2010). Undoing privilege: Unearned advantage in a divided world. New York: Palgrave Macmillan.

Twine, F. W., \& Gardener, B. (2013). Geographies of privilege. New York: Routledge.

Valentine, G. (2000). Exploring children and young people's narratives of identity. Geoforum, 31(2), 257-267.

Wildman, S., \& Davis, A. (1995). Language and silence: Making systems of privilege visible. Santa Clara Law Review, 35, 881-906.

The opinions expressed are those of the paper author(s) and not He Rourou or The Mind Lab.

He Rourou by The Mind Lab is licensed under a Creative Commons Attribution-NonCommercial-ShareAlike 4.0 International License, except where otherwise noted. [ISSN 2744-7421]

\section{About the Author}

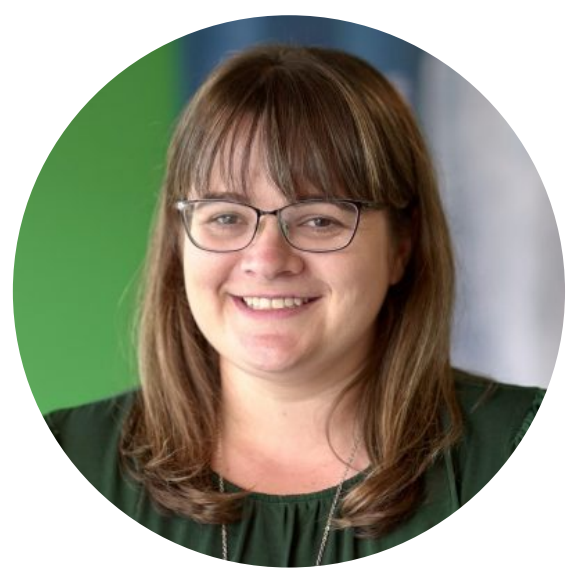

Hayley Sparks

After graduating with a PhD in Geography from The University of Auckland in 2018, Hayley joined The Mind Lab and currently holds the role of National Academic Manager. Hayley's $\mathrm{PhD}$ was titled 'Elite education and everyday encounters: Examining the multiple dimensions of privilege in young people's lives' and was the origin of this article. Her research interests primarily sit at the intersection of geography and education and understanding relationships between people and place; inequities and structures of privilege in education, the role of digital technology in education, and the value of practice based research. Email: hayley.sparks@themindlab.com 